\title{
A NOVEL ONLINE APPROACH FOR JAZZY JEWELS
}

\author{
Subha $\mathrm{J}^{1}$ Sujitha $\mathrm{S}^{2}$ Subalakshmi $\mathrm{K}^{3}$ \\ ${ }^{1}$ Department of Computer Application,Francis Xavier Engineering \\ College,Tamil Nadu, Tirunelveli \\ ${ }^{2}$ AP/Department of Computer Application,Francis Xavier Engineering \\ College,Tamil Nadu, Tirunelveli \\ ${ }^{3}$ Department of Computer Application,Francis Xavier Engineering \\ College, Tamil Nadu, Tirunelveli
}

\begin{abstract}
The objective of this software is to enable a Jeweller manage all their business workflow through an automated software system which brings more efficiency to their business and interactive/transparency to the user. It also provides automated tools that can be used for Online purchasing and order. Jewellery Automated System can be user friendly between the Jewellery shops and their clients
\end{abstract}

\section{KEYWORDS}

Ec,c2c,mas,rdbms, gnu

\section{INTRODUCTION}

It is open that most of the people are seeking to buy items every day in most cities and towns, both locally and abroad, desperate if they might get a solution or a right person to deliver a solution to them. These people end up settling at items or service providers who are fraud or who sell illegal and fake items to the desperate buyers.There are legit business people and store owners who have quality items in the locality of the auctioneer, but they do not meet for business because the auctioneer is not informed about the items available. This is a great frustration in deed!This project shall handle this issue by creating an online platform where a user will be able to post items online for auction. The items will accompany item name, selling price, and a picture presentation for the bidder to see. The bidder, if interested in the item, will make the auction for the product and will be able to inspect the item physically to make an approvement about the product then complete the business with the seller.People are always on the go to their renown product supplier, or nearby market center or at times a local hawkers, who goes on to supply items and at times when he cannot get the item the buyer wants, mostly they give their hands to get them items and at times they mess and bring fake and quarks deliver stolen and bad items. This is because unqualified people offer delivery of items to customers.Due to the disparity of the buyers, scammers have always taken the advantage to offer item delivery to the customers. Many fake items have found their way into the hands of the people, or buyers remain in the same condition of lack, as they don't get the correct products from the sellers. Sometimes buyers struggle to find the right items, in failure, and they seek to get back to their homes.The customers will be assured of getting the right products, since they will take their time to analyses and compare a range of listed items and choose appropriately according to their need or desire.This 
will save time that buyers take in search of items and therefore they will save themselves from worsening of conditions which may lead to wastage of time conditions. This will also save money that is spend around travelling and bidding for the undesired items.

Elementary education besides being a basic human need is vital for raising the standard of life, providing gainful employment, removal of regional backwardness, thereby ensuring overall development and wellbeing of a country. It is therefore the need of the hour to review the literature carried out by different academicians, educational thinkers, researchers, policymakers and educational reformers in the field of education Among our findings, we uncover an important correlation among sniping and high surplus ratios, which implies the uncertainty of true value in a competitive environment. The key issue is the wrong assumption that bidder's valuations are independent from each other, which leads to inefficient auctions. In order to address the inefficiencies of current online formats we introduce a declining price auction model customized for online transactions. Conceptually, this model ought to deal with the complexities of competition in an online environment while maximizing social welfare. [1 ]The online auction does not take place face to face which creates anonymous bidders. The auctioneers cannot have a hold on who is participating in the bidding. This can lead to anonymity in identifying the bidders and further in shill bidding. By predicting the end-bid price of product and keeping it concealed from bidders, bids can be analyzed against the predicted price or range of it and if any unpredictable unexpected bid is occurred, then the respective bid can be treated as shilled or fake one and can be ignored..[2]Online auction is becoming more and more popular in electronic commerce (EC). It has become the mainstream trading methods in consumer to consumer (C2C), such as eBay. The steady collaboration field and common concept of exchange ;may be formed in the cooperation of the MultiAgent system (MAS), and then the agents will have so much common knowledge in order to complete the tasks. The member of MAS has both cooperation and self-interest. Based on the analysis of the cooperation and competition of the participators in the online auction, the concept of overtime and history information is introduced. As existing consider the history information. This paper put forward a MAS flow frame and negotiation algorithms that make the bidders of the auction participate in the negotiation honestly and actively. Both the efficiency and transparency among the participators have been enhanced. [3]Online auction are among the most significant e-business applications. Their impact on trading in business to business, as well as in the business to consumer and consumer to consumer fi eld. Day to Day use of Online Auction is increases. Customers are moving toward to online Auction for purchasing and selling items. Quite a few companies have started projects of their own, trying to improve their purchasing and sales channels.[4]With the added convenience of online transactions also comes the risk of electronic fraud. Although companies such as eBay have operated for the last 10 - 15 years, very little auction data has been collected and made publicly available or analysed, to the knowledge of the authors. Before any assertions about the amount of fraud in online auctions can be made, the underlying nature and structure of online auctions must be understood.[5] 


\section{Architecture Diagram}

\section{ARCHITECTURE DIAGRAM}

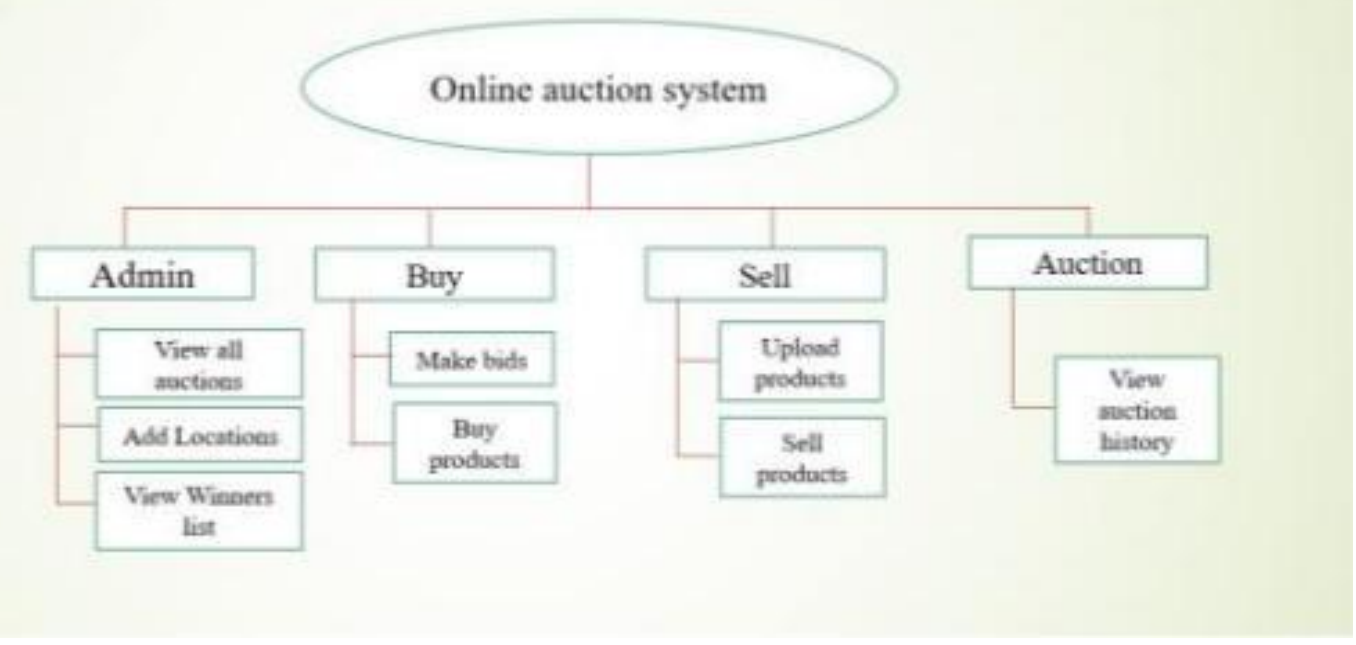

Figure 1 Architecture diagram

\section{Problem Statement}

\section{Modules}

\section{Admin}

- Admin has the following privileges. Admin can add the new agents(Employees) and new design and various offer categories.

- Admin can update his profile and types and cost of Jewellery. He can delete the agents and some jewel categories.

- Admin can view all the agents' details and booking details. He can generate reports for ad bookings and customer details.

\section{Agent}

- Agent must be login to perform his activities. He has the following privileges. Agent can add the customers.

- He can update his profile and change his password. He can view all the customer details and booking details.

- Agent will interact with Customers or clients queries and request.

\section{Customer}

- Every user must be a registered person. After registration he gets his own username and password. By using this username and password only user can 
logon into the system. If the user name and password is invalid the request is thrown back.

- User can view all the new designs uploaded by the Jewel shops. Based on the interest he can order the jewels through online itself by confirming the advance payments. Also user can uploaded their own design requirements to employees for the further proceedings.

\section{Database}

- MySQL is an open-source relational database management system (RDBMS).

- MySQL is free and open-source software under the terms of the GNU General Public License, and is also available under a variety of proprietary licenses.

- MySQL is a fast, easy-to-use RDBMS being used for many small and big businesses.

- MySQL is developed, marketed and supported by MySQL AB, which is a Swedish company. MySQL is becoming so popular because of many good

\section{EXPERIMENT AND RESULTS}

\section{Output Screen}

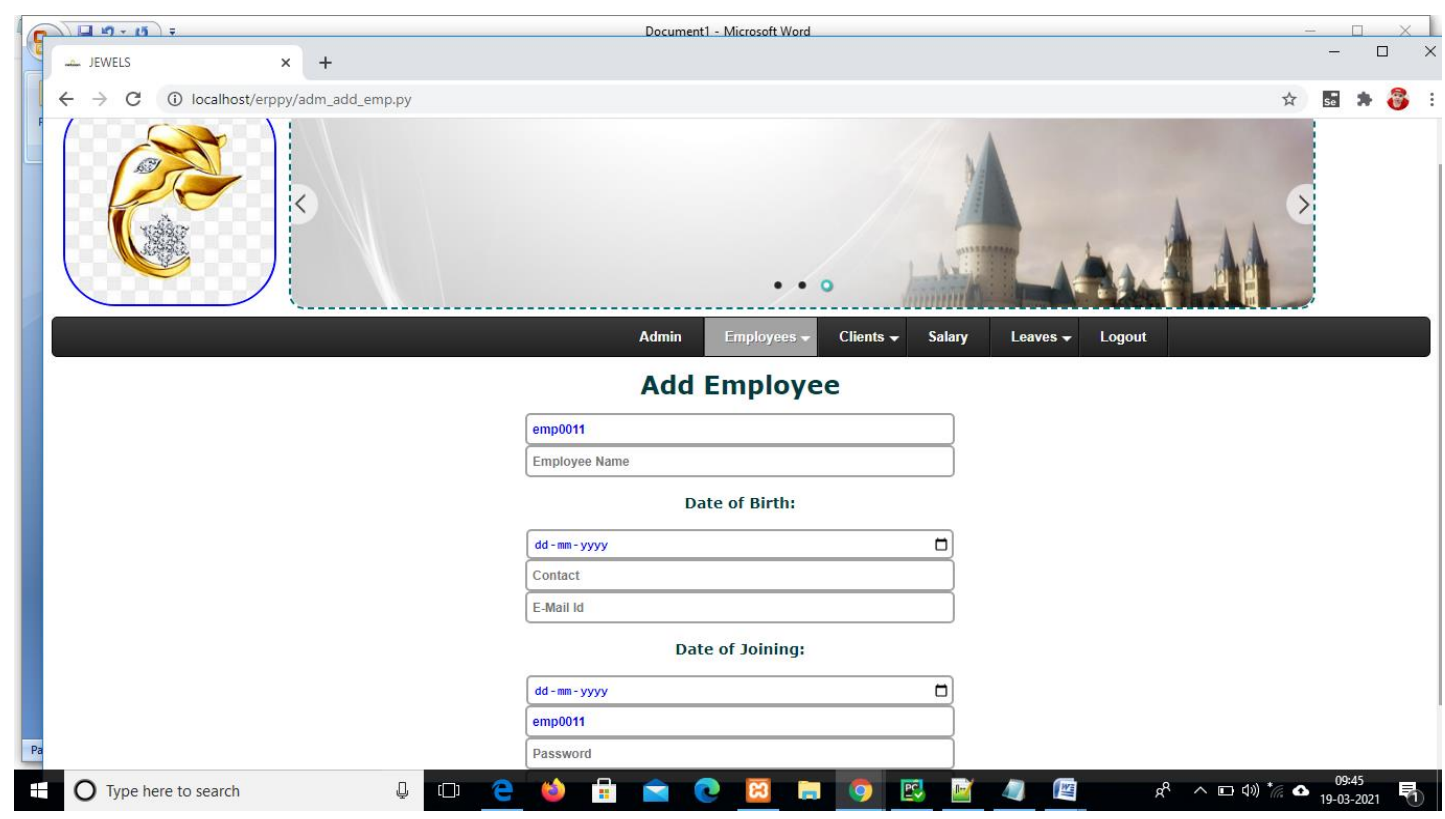

Figure 2 Employee Details 


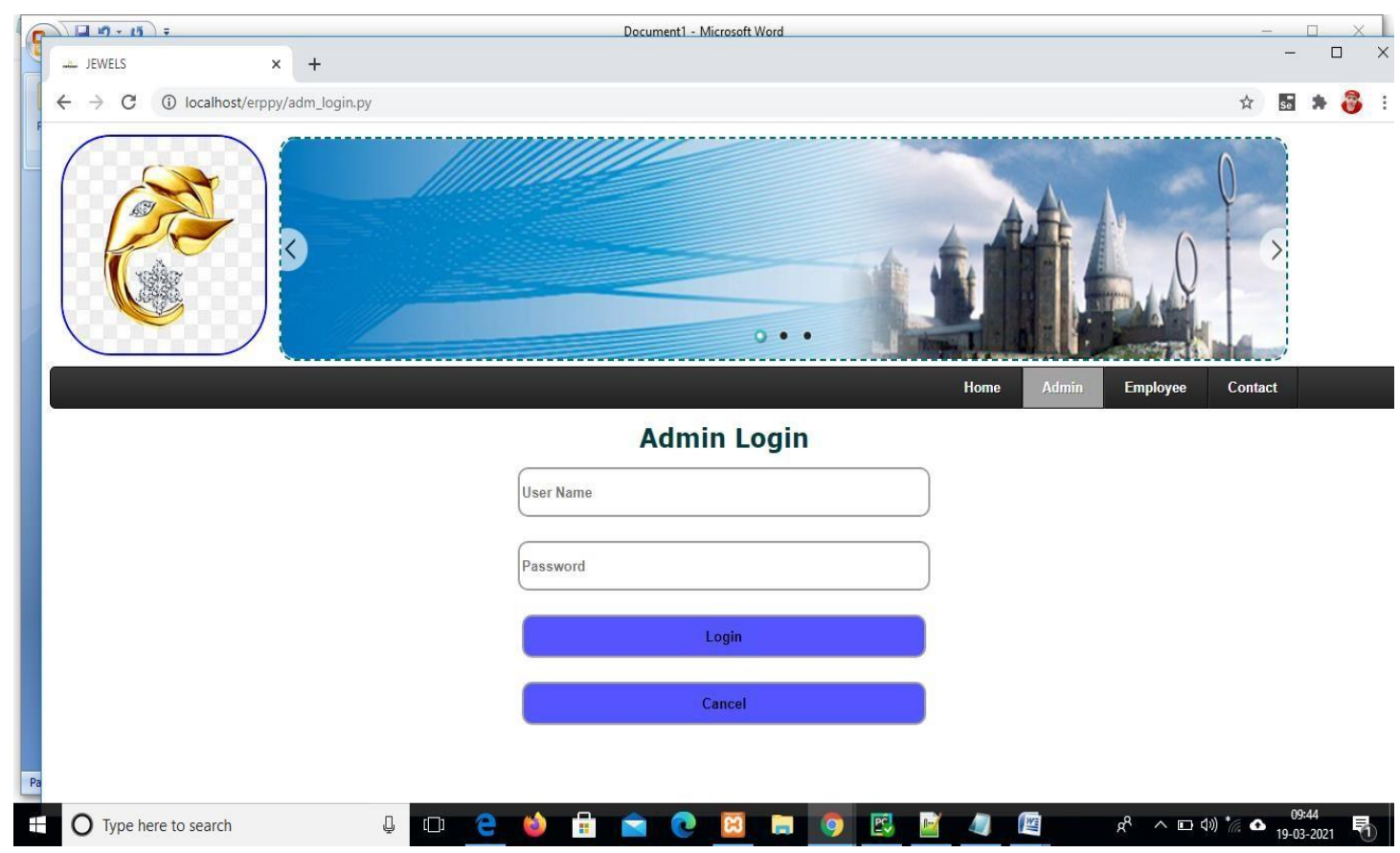

Figure 3 Admin Login

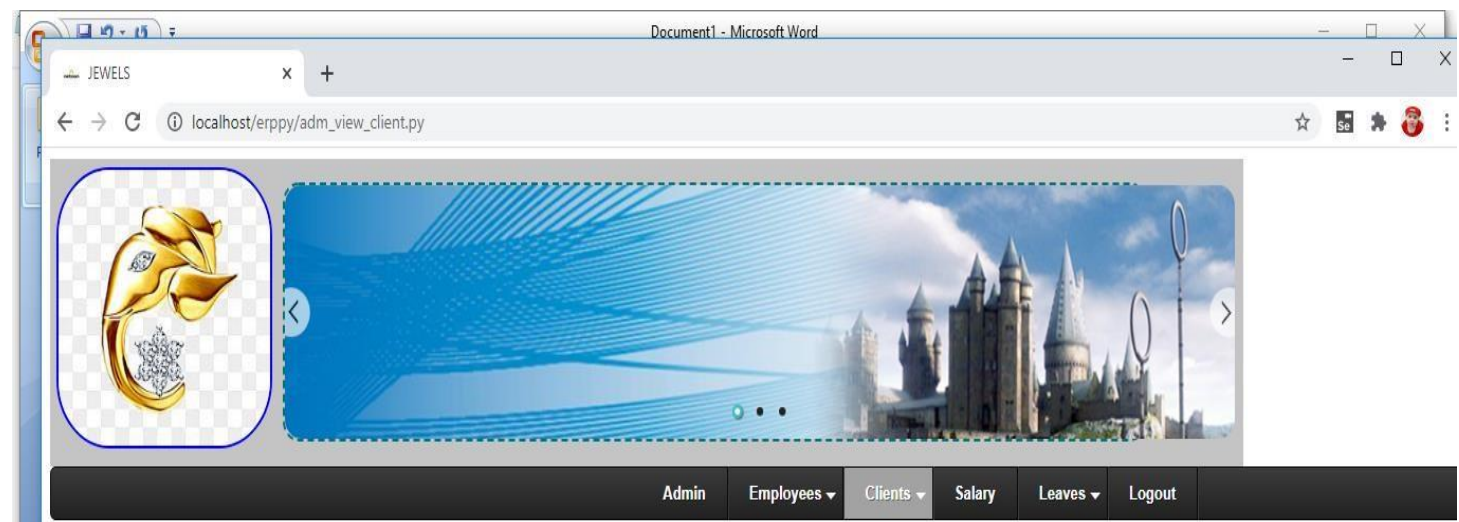

Client Details

\begin{tabular}{|l|l|l|l|l|l|l|l|}
\hline S.No. & Client Id & Category & Contact & \multicolumn{1}{|c|}{ E-mail Id } & \multicolumn{1}{|c|}{ Address } & \multicolumn{1}{c|}{ City } & \multicolumn{1}{c|}{ DoM } \\
\hline 1 & client0001 & Individual & 8765432190 & malini@gmail.com & $\begin{array}{l}\text { Saibaba } \\
\text { colony,Coimbatore. }\end{array}$ & Malini & $\begin{array}{l}\text { Saibaba } \\
\text { colony,Coimbatore. }\end{array}$ \\
\hline 2 & client0002 & Individual & 9876543211 & kasthuriAAA@gmail.com & Madurai & Kasthuri & Madurai \\
\hline 3 & client0003 & Individual & 9876543210 & karth@@gmail.com & Coimbatore & Karthi & Coimbatore \\
\hline \hline
\end{tabular}

Figure 4 Client Details 


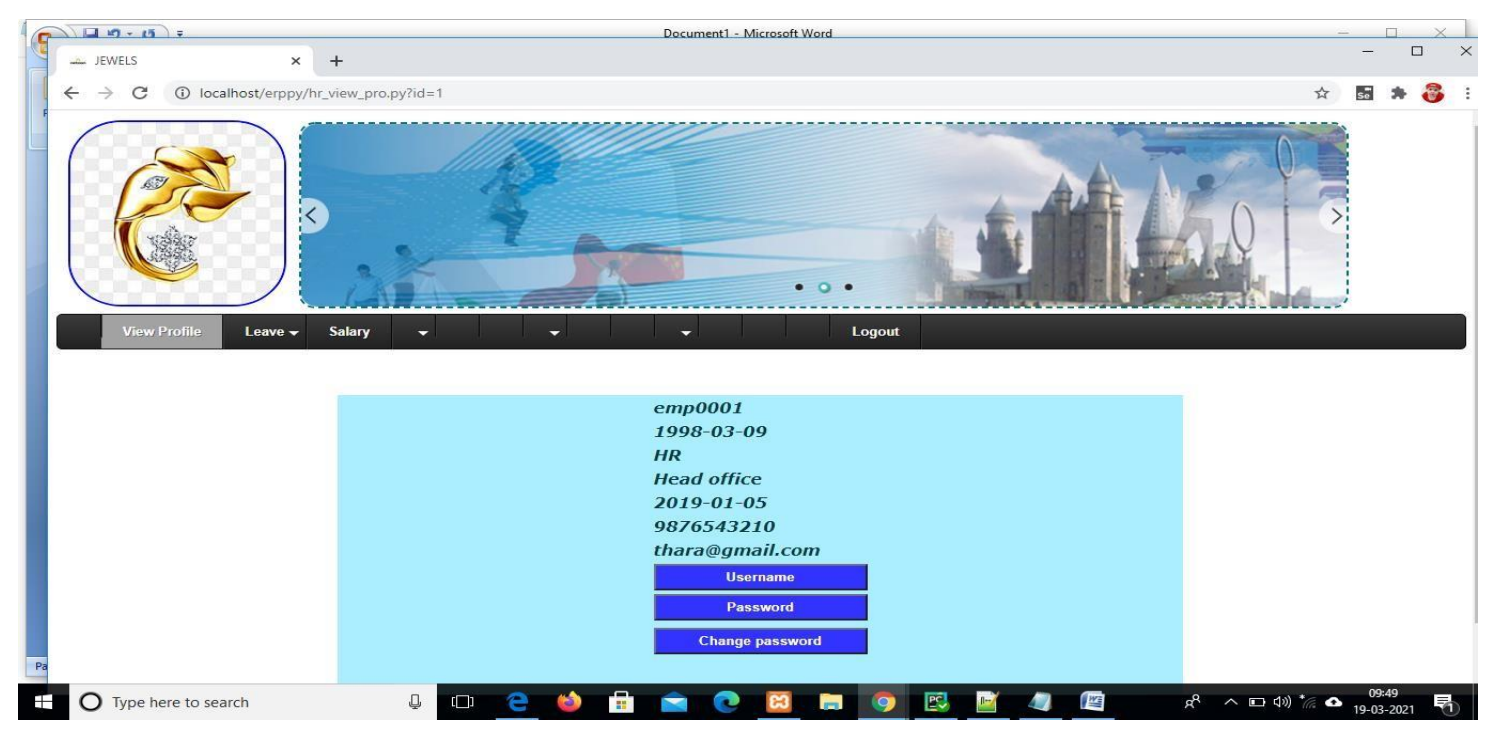

Figure 5 Employee Profile

\section{Performance analysis}

The existing and proposed system are analysed. The problem identified in exsiting is an admin panel by which an admin can control the whole bidding system. Admin can manage all the auction processes and also control the registered customers. There is fixed delivery policy. After finishing the bidding process, the won bidders can buy the product bymake online payment. This is a fully dynamic system which can be easily operated by the users This assumption has prevented them from automating.Nearly $70 \%$ performance has been increased

\section{CONCLUSION}

Online auction has made the interested biddersfrom being physically present in auction houses. The auction website provides variety of products online which gives many choices to the bidders to select the product of their interest. The products are placed according to their location.

\section{FUTURE ENHANCEMENTS}

Online Auction System has made consumers moreeffective and efficient in their behaviour and hasdriven businesses to a new level. Though thebuyers can view his status in our website, they are not otified when he won the auction.So further notifications like email and SMS can be made as future enhancements.

\section{REFERENCES}

[1]. Farooq M, Hasan M, Gull F, Mycobial deterioration of stone monuments of Dharmarajika, Taxila, Journal of Microbiology \& Experimentation, Vol. 2(1). Pp. 36-412015.

[2]. Kalaskar, P.G., Zodpe, S.N. Biodeterioration of library resources and possible approaches for their control. International journal of applied research. Vol. 2(7). Pp. 25-33. 2016.

[3] Patidar D. and Soni A. Indigenous material of preserving manuscripts in library. International Journal of Research in Library Science. Vol. 2(2). Pp. 183-187. 2016. 
[4] Thiyam Satyabati Devi, Impact of Information Technology on the Societal Archive: A Case Study of Manipuri Manuscripts, International Information and Library Review, Vol.40 (3). Pp. 179-184. 2008

[5] Bakkali, F., Averbeck, S., Averbeck, D. and Idaomar, M. Biological effects of essential oils-A review. Food and Chem. Tox., Campden BRI, Gloucestershire UK Publication Vol. 46. Pp. 446-475. 2008.

[6]. Manasi Bhamare, Arati Chame, Gaurav More Prof Amol Rindhe," Online Auction".

[7]. Geetanjali Sawant, Ganesh Bane, Akshay Gurav ,Swaraj Pawar, "Survey on Online Auction System”.

[8]. Patidar D. and Soni A. Indigenous material of preserving manuscripts in library. International Journal of Research in Library Science. Vol. 2(2). Pp. 183-187. 2016.

[9]. Rashesh G Chothani, Punit R Patel , “A Review of

Online Auction and It's Pros and Cons “.

[10]. Rodel Balingit, Jarrod Trevathan and Wayne Read,

"Analysing Bidding Trends in Online Auctions".

\section{AUTHORS}

Subha $\mathbf{J}$ doing final year MCA in Francis Xavier Engineering College

Ms. S. Sujitha working as Assistant Professor in the Department of Computer Applications, Francis Xavier Engineering College. Her area of interest is Wireless Sensor networks
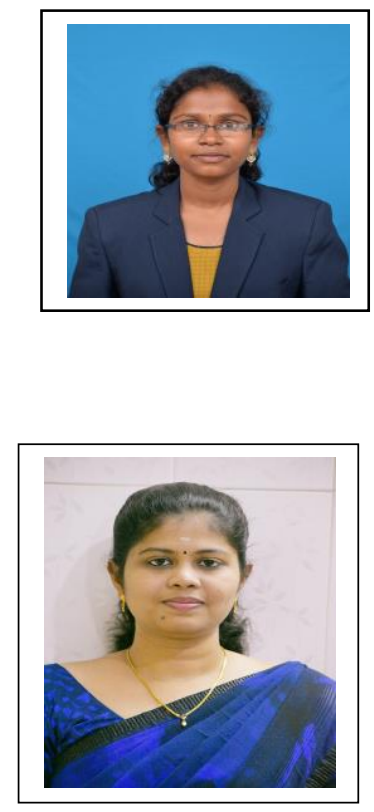

Subalakshmi K doing first year MCA in Francis Xavier Engineering College

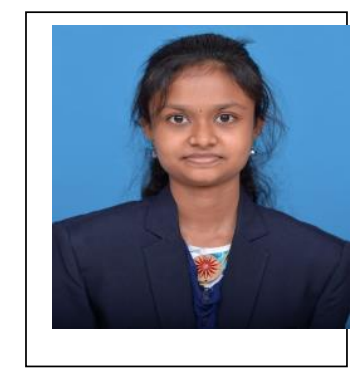

